\title{
Malignant ovarian germ cell tumors in pediatric patients: The AIEOP (Associazione Italiana Ematologia Oncologia Pediatrica) study
}
M. Terenziani ${ }^{1}$
G. Bisogno²
R. Boldrini ${ }^{3}$
G. Cecchetto ${ }^{4}$
M. Conte ${ }^{5}$
L. Boschetti ${ }^{1}$
M.D. De Pasquale 6
D. Biasoni ${ }^{7}$
A. Inserra ${ }^{8}$
F. Siracusa9
M.E. Basso ${ }^{10}$
F. De Leonardis ${ }^{11}$
D. Di Pinto ${ }^{12}$
F. Barretta ${ }^{13}$
F. Spreafico ${ }^{1}$

\section{P. D'Angelo ${ }^{14}$}

\begin{abstract}
${ }^{1}$ Pediatric Oncology Unit, Fondazione IRCCS Istituto Nazionale dei Tumori di Milano, Italy

${ }^{2}$ Pediatric Unit, University-Hospital of Padua, Padova, Italy

${ }^{3}$ Pathology Unit, Ospedale Pediatrico Bambino Gesù-IRCCS. Roma, Italy

${ }^{4}$ Pediatric Surgery Unit, University-Hospital of Padua, Padova, Italy

${ }^{5}$ Oncology Unit, Ospedale Pediatrico G. Gaslini, Genova, Italy

${ }^{6} \mathrm{Hematology/Oncology} \mathrm{Department,} \mathrm{Ospedale}$ Pediatrico Bambino Gesù-IRCCS, Roma, Italy

${ }^{7}$ Pediatric Surgery Unit, Fondazione IRCCS Istituto Nazionale dei Tumori di Milano, Italy

${ }^{8}$ Pediatric Surgery Department, Ospedale Pediatrico Bambino Gesù-IRCCS, Roma, Italy

${ }^{9}$ Pediatric Surgery Department, Università of Palermo, Palermo, Italy

${ }^{10}$ Hematology/Oncology Unit, Ospedale Infantile Regina Margherita, Torino, Italy

${ }^{11}$ Division of Pediatric Hematology-Oncology, University of Bari, Italy

${ }^{12}$ Pediatric Oncology Unit, Seconda Università, Napoli, Italy

${ }^{13}$ Unit of Clinical Epidemiology and Trial Organization, Fondazione IRCCS Istituto Nazionale dei Tumori di Milano, Italy

${ }^{14}$ Hematology/Oncology Unit, A.R.N.A.S Civico Di Cristina e Benfratelli, Palermo, Italy

Correspondence

Monica Terenziani, Pediatric Oncology Unit, Fondazione IRCCS Istituto Nazionale dei Tumori, via Giacomo Venezian 1, 20133 Milano, Italy. Email:monica.terenziani@istitututotumori.mi.it
\end{abstract}

\begin{abstract}
Objective: Malignant ovarian germ cell tumors (MOGCT) carry an excellent prognosis, and the treatment aims to achieve results with the least possible treatment-related morbidity. The aim of this study was to assess the outcomes of pediatric patients with MOGCT.

Methods: Patients were treated according to their stage: surgery and surveillance for stage I; a modified bleomycin-etoposide-cisplatin (BEP) regimen for stages II (three cycles), III, and IV (three cycles) with surgery on residual disease.

Results: Seventy-seven patients were enrolled (median age 11.8 years), 26 with dysgerminoma (Dysg), 13 with immature teratoma and elevated serum alpha-fetoprotein levels (IT + AFP), and 38 with nondysgeminoma (Non-Dysg) staged as follows: 27 stage I, 13 stage II, 32 stage III, 5 stage IV. Among evaluable patients in stage I (5-year event-free survival [EFS] $72.1 \%$ [95\% Cl: 56.4-92.1\%]; 5 -year overall survival [OS] 100\%), seven relapsed (three patients with Dysg and four patients with Non-Dysg) and were rescued with chemotherapy (plus surgery in three patients). Among the evaluable patients with stages II-IV, 48 (98\%) achieved complete remission after chemotherapy \pm surgery, one (IT + AFP, stage IV) had progressive disease. In the whole series (median follow-up 80 months), the 5-year OS and EFS were $98.5 \%$ (95\% Cl: $95.6-100 \%)$ and $84.5 \%$ (95\% Cl: $76.5-$ 93.5\%).
\end{abstract}

Conclusions: We confirm the excellent outcome for MOGCT. Robust data are lacking on surgical staging, surveillance for Non-Dysg with stage I, the management of IT + AFP, and the most appropriate BEP regimen. As pediatric oncologists, we support the role of surveillance after proper surgical staging providing cases are managed by experts at specialized pediatric centers.

\section{KEYWORDS}

childhood, germ cell tumors, ovarian 


\section{1 | INTRODUCTION}

Malignant ovarian germ cell tumors (MOGCT) are rare, accounting for $2-3 \%$ of all ovarian malignancies. They usually develop in children and adolescents, or young women ${ }^{1}$ with a median age at diagnosis of 16 years (range 6-60 years). Patients are treated at pediatric departments as well as gynecology units. An initial surgery may also sometimes be managed at nonspecialized centers, and inadequate surgical staging is common. ${ }^{2}$ Luckily, the survival rates for children with malignant germ cell tumors (GCT) generally have greatly improved.

Based on a previous national experience, ${ }^{3}$ a new study on malignant non-CNS GCT launched by the Associazione Italiana Ematologia Oncologia Pediatrica (the "TCGM-AIEOP-2004 study") aimed to extend the age of enrolment from $\leq 16$ to $<18$ years, to avoid further treatment after surgery for all localized (stage I) MOGCT, and to adopt standard combination chemotherapy (bleomycin-etoposide-cisplatin, BEP) with dose adjustments to limit late effects. The present study examines the outcomes.

\section{2 | METHODS}

Patients with MOGCT were registered for the second national prospective protocol as part of the TCGM-AIEOP-2004 study. The protocol was approved by the local ethical committees.

Patients under 18 years of age with histologically proven MOGCT (dysgerminoma [Dysg] or nondysgerminoma [Non-Dysg], i.e., yolk sac tumor [YST], embryonal carcinoma; choriocarcinoma, immature teratoma [IT] with elevated serum alpha-fetoprotein [AFP] levels for age, without any cutoff, or mixed forms with two or more components) were enrolled. Patients with no tumor histology at diagnosis, but with high AFP and/or beta-human chorionic gonadotropin (betaHCG) levels could also be included. AFP and betaHCG were assayed at diagnosis, before each cycle of chemotherapy, or until normalization after completing the treatment(s). Patients were followed up with abdominal ultrasound, chest X-rays, and AFP and betaHCG assay every 2 months in the first year after completing any treatment, every 3 months in the second year, then 6-monthly until the fifth year. After the fifth year, follow-up was at the discretion of the local center. Staging was done with the modified Children's Oncology Group system ${ }^{4-8}$ (Table 1). Centralized pathology review was encouraged, but not mandatory.

\section{1 | Treatment}

Patients underwent initial surgery (biopsy or oophorectomy [OO]). Initial $\mathrm{OO}$ was recommended when complete resection was judged feasible. The procedure included complete resection of the ovary involved (without violating the tumor capsule), sparing the unaffected fallopian tube, peritoneal washing cytology (PWC), visual inspection of the opposite ovary with biopsy of suspected nodules, infracolic omentectomy, biopsy of any suspect areas, and lymph node sampling (LNS). After February 2013, the approach was modified, omitting omentectomy and LNS, with palpation of the retroperitoneal lymph node, and biopsy if abnormally enlarged. Biopsy was recommended if complete resection was unfeasible, and $\mathrm{OO}$ was mandatory at the end of chemotherapy.

Treatments depended on stage: patients with stage I, any histology, and tumor markers returning to normal after surgery, remained under surveillance without any chemotherapy. The others received a modified BEP regimen (cisplatin $25 \mathrm{mg} / \mathrm{m}^{2}$ daily on days $1-4$; etoposide $100 \mathrm{mg} / \mathrm{m}^{2}$ daily on days $1-4$; bleomycin $15 \mathrm{mg} / \mathrm{m}^{2}$ on day 2 , once per cycle), every 21 days (three cycles for stage II, four for stages III and IV, or persistently high markers after surgery). After chemotherapy, resection of radiologically evident residual disease was suggested. Bilateral disease was managed surgically, sparing the less-involved ovary to avoid castration.

\section{2 | Response criteria}

Patients with normal tumor markers and no imaging abnormalities were classified as complete remissions (CR). Patients with negative imaging and lower tumor markers, or with imaging abnormalities at the primary tumor/regional sites and declining/normalizing tumor markers, were classed as partial remissions (PRs). Patients with a more than $25 \%$ increase in tumor size, new lesions, and/or rising tumor markers were classified as progressive disease (PD). Patients with PR and residual tumor underwent surgical exploration, and postoperative assessments depended on histological findings, classified as fibronecrotic tissue residual teratoma and viable malignant cells. ${ }^{4}$

\section{3 | Statistical analysis}

Overall survival (OS) was defined as the time elapsing from diagnosis to death from any cause. Time was censored as at the last followup for patients still alive. Event-free survival (EFS) was defined as the time from diagnosis to any event (malignant germ cell recurrence, teratoma, teratoma with malignant transformation, death, whichever occurred first). Time was censored as at the last follow-up for patients still alive and event-free. The OS and EFS curves were estimated using the Kaplan-Meier method, ${ }^{9}$ and compared using the log-rank test. All patients were included in the OS and EFS analyses regardless of whether they complied with the treatment program. EFS was censored at 1 month for two patients (the time elapsing from diagnosis to last follow-up), but their survival status could be retrieved from the records, and they could contribute to the OS curves as censored observations for a longer interval. The median follow-up was estimated with the reverse Kaplan-Meier method, using the OS data. ${ }^{10}$

\section{3 | RESULTS}

From March 2004 to December 2015, 77 patients were accrued from 17 institutions, with a median age of 11.8 years (range 1.8-17.2), and a median follow-up of 80 months (range 14-149). Four females had chromosomal abnormalities (Turner syndrome in two, Proteus syndrome in one, a constitutional 8-22 translocation in one) and three had relatives with tumors (a sister with ovarian teratoma, a father with seminoma, a brother with low-grade glioma). Patients were staged as follows: 27 stage I (35\%), 13 stage II (17\%), 32 stage III (42\%), and 
TA B LE 1 Staging of malignant ovarian germ cell tumors (modified according to the Children's Oncology Group)

\begin{tabular}{|c|c|}
\hline Stage & Description \\
\hline I & $\begin{array}{l}\text { Limited to ovary, peritoneal washing negative for malignant cells; no clinical, radiological, or histological evidence of disease beyond } \\
\text { the ovaries (gliomatosis peritonei did not result in upstaging); tumor markers negative after appropriate half-life decline }\end{array}$ \\
\hline II & $\begin{array}{l}\text { Microscopic residual or positive lymph nodes }(<2 \mathrm{~cm} \text { ); peritoneal washing negative for malignant cells (gliomatosis peritonei did not } \\
\text { result in upstaging); tumor markers positive or negative }\end{array}$ \\
\hline III & $\begin{array}{l}\text { Gross residual or biopsy only, tumor-positive lymph node(s) }>2 \mathrm{~cm} \text { in diameter; contiguous visceral involvement (omentum, intestine, } \\
\text { bladder); peritoneal washing positive for malignant cells; tumor markers positive or negative }\end{array}$ \\
\hline IV & Distant metastases, which may include liver and/or persistent elevation of tumor markers ${ }^{a}$ \\
\hline
\end{tabular}

5 stage IV (6\%). The histotype distribution was as follows: 26 Dysg (34\%), and 38 Non-Dysg (49\%), and 13 (17\%) IT (Grade 2 in six, Grade 3 in seven) with elevated AFP levels (median $140 \mathrm{ng} / \mathrm{ml}$, range $50-3,863$ ). Central pathology review was performed for 38 of 77 (49\%) cases and all but two diagnoses were confirmed (Table 2).

Dysg: Among 26 patients, 13 were stage I. One patient was lost to follow-up after 1 month of observation; all the others were monitored closely after surgery. Five patients had surgery according to the original guidelines, five according to the revised version, two underwent OO, and one unknown. Three patients (one without PWC, two properly staged) relapsed 21,25 , and 40 months after their diagnosis (Table 3); all three are alive in CR, after chemotherapy in two cases, and after chemotherapy plus subsequent surgery with no impact on fertility in one. The six stage II cases underwent surgery and three cycles of BEP chemotherapy, all achieving CR. The reason for staging them as II were as follows: metastatic lymph nodes in two, malignant cells in peritubaric tissue in two, and tumor rupture in two.

The reason for seven cases being stage III were metastatic lymph nodes in three, PWC positive in two, and residual disease in two. Six patients received four cycles of chemotherapy, achieving $C R$. One achieved PR after biopsy and BEP, then underwent delayed surgery revealing viable malignant cells. For all Dysg patients, the 5-year OS was $100 \%$, and the 5 -year EFS was $86.6 \%$ overall ( $95 \% \mathrm{Cl}$ : $73.4-100 \%$ ), and $72.9 \%$ (95\% Cl: $50.7-100 \%$ ) and $100 \%$ for stage I and stages II and III, respectively.

IT \pm AFP: Three females with stage I (AFP: 65, 97, 3,863) were monitored closely after surgery and no chemotherapy. One had surgery according to the original guidelines, two according to the revised version; none relapsed. One patient with stage II (AFP 178) had peritoneal implants totally removed and chemotherapy; she was alive in CR.

The reason for eight cases (AFP: 50-1,438) being classified as stage III were as follows: peritoneal implants and/or residual mass in five, PWC positivity in two, unknown in one. One patient was lost to followup after one cycle of chemotherapy; six achieved CR after chemotherapy, one achieved PR (normalized tumor markers and gross residual disease) and underwent surgery revealing teratoma. One female developed multiple pelvic peritoneal nodules of mature teratoma after 47 months (Table 3).

The one stage IV case had liver and peritoneal metastases (AFP: 1,440). After surgery, and two BEP cycles, she had PD, so the chemotherapy was changed, achieving PR. Teratoma was identified after delayed surgery. Thirty-four months after diagnosis, the residual infradiaphragmatic disease spread rapidly and she died after an attempted resection. Pathology showed teratoma with malignant transformation (primitive neuroectodermal tumor [pNET]; Table 3).

In all IT + AFP patients, the 5-year OS and EFS rates were $92.3 \%$ (95\% Cl: 78.8-100\%) and 82.5\% (95\% Cl: 63.1-100\%), respectively.

Non-Dysg: Among 38 patients, 11 were stage I and were monitored closely after surgery, and had no chemotherapy. Two had surgery according to the original surgical guidelines, seven according to the revised version, two underwent OO. Four patients relapsed (one without PWC, one without normalized AFP after surgery, two properly staged) a median 3 months after diagnosis (Table 3). They all received chemotherapy, and two of four patients also had surgery (one before, one after chemotherapy), with no impact on fertility. All are alive and in CR.

Six cases were classified as stages II due to tumor ruptures/capsule lacerations in three, peritoneal pelvic implants were removed in one, no PWC in two. One patient was PD after two BEP cycles, with a growing tumor mass despite marker normalization. She underwent surgery, teratoma with malignant transformation was diagnosed, and chemotherapy was administered. The diagnosis was centrally revised to growing teratoma and managed surgically. The teratoma grew again twice. At the time of writing, she was disease-free after a 82-month follow-up (Table 3). All patients achieved CR: five after three cycles of BEP, one after chemotherapy and surgery.

The reasons for 17 patients being stage III were as follows: residual mass and/or peritoneal implants in eight, PWC positivity in three, metastatic lymph nodes in three, and because no PWC was performed after tumor rupture in three. Thirteen (76\%) achieved CR after chemotherapy. Four (24\%) had PR (normalized tumor markers and gross residual disease) and underwent surgery, revealing teratoma in two and fibronecrotic tissue in two.

No stage III patients relapsed with malignant disease. One relapsed twice with growing teratoma, 11 and 39 months after delayed surgery (Table 3). Among the four patients with stage IV, two were under 11 years of age and had lung metastases, two were older, and one had liver metastases, the other had elevated AFP and betaHCG levels, and unreported sites of metastases. All but one of these patients underwent $\mathrm{OO}$ and received chemotherapy. There were two CR and two PR (with normalized markers), one with lung and the other with ovary involvement. Lung metastasectomy revealed viable malignant cells and, after two more BEP cycles, the patient was alive and disease-free 32 months after diagnosis. OO identified teratoma in the other. Overall, there were two $\mathrm{CR}$, one teratoma, and one case of viable malignant cells. All patients are alive and in CR. The 5-year OS for all Non-Dysg patients 
TAB LE 2 Clinical and pathologic characteristics of patients with MOGCT

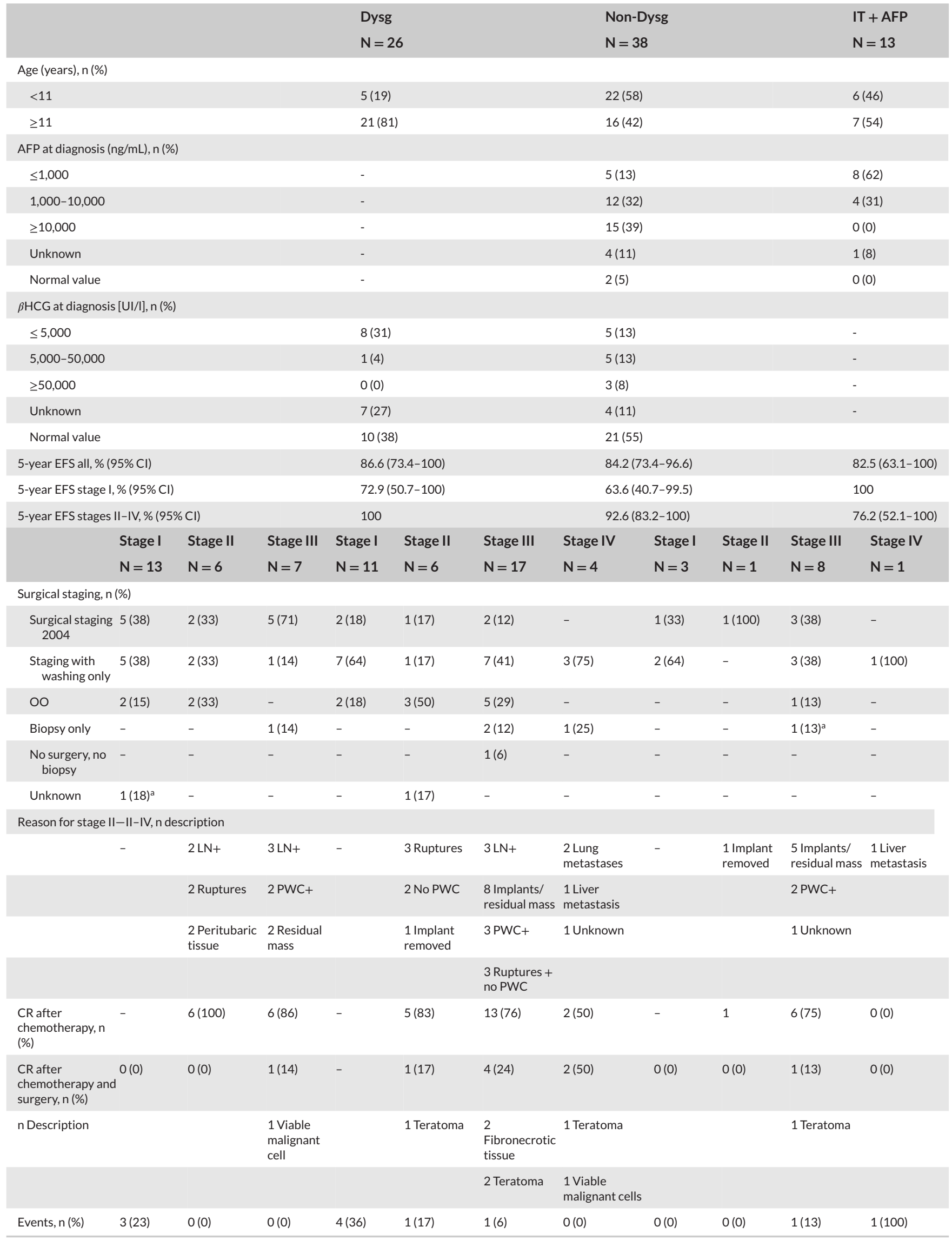

a Lost to follow-up; LN+, metastatic lymph nodes; PWC+, PWC with malignant cells. 
TABLE 3 Events in patients all stages

\begin{tabular}{|c|c|c|c|c|c|c|c|c|c|c|}
\hline $\begin{array}{l}\text { Age } \\
\text { (years) }\end{array}$ & $\begin{array}{l}\text { Primary } \\
\text { tumor } \\
\text { histology }\end{array}$ & $\begin{array}{l}\text { Stage and } \\
\text { markers at } \\
\text { diagnosis }\end{array}$ & $\begin{array}{l}\text { Adherence to } \\
\text { surgical } \\
\text { staging }\end{array}$ & Treatments & EFS (months) & $\begin{array}{l}\text { Event } \\
\text { histology }\end{array}$ & Site & Status & $\begin{array}{l}\text { Treatment } \\
\text { event }\end{array}$ & $\begin{array}{l}\text { OS } \\
\text { (months) }\end{array}$ \\
\hline 16 & Dysg & I Normal values & Yes & Surveillance & 40 & Dysg & Lymph nodes & $\mathrm{CR}$ & $\begin{array}{l}\text { Biopsy, BEP } \times \\
4 \text { cycles }\end{array}$ & 102 \\
\hline 9 & Dysg & I Not done & No & Surveillance & 25 & Dysg & Pelvic mass & $\mathrm{CR}$ & $\begin{array}{l}\text { Biopsy, BEP } \times \\
4 \text { cycles }\end{array}$ & 113 \\
\hline 6 & Non-Dysg & $\begin{array}{l}\text { I } \\
\text { AFP- } \\
\text { betaHCG }\end{array}$ & Yes & Surveillance & 3 & Not done & $\begin{array}{l}\text { AFP- } \\
\text { betaHCG }\end{array}$ & CR & BEP $\times 4$ cycles & 80 \\
\hline 3 & Non-Dysg & Not done & No & Surveillance & 3 & Non-Dysg & $\begin{array}{l}\text { Peritoneal } \\
\text { implants, } \\
\text { AFP- } \\
\text { betaHCG }\end{array}$ & $\mathrm{CR}$ & $\begin{array}{l}\mathrm{S} \rightarrow \mathrm{BEP} \times 6 \\
\text { cycles }\end{array}$ & 103 \\
\hline 9 & Non-Dysg & AFP & Yes & Surveillance & 3 & Not done & $\begin{array}{l}\text { Liver } \\
\text { metastases, } \\
\text { peritoneal, } \\
\text { implants, AFP }\end{array}$ & $\mathrm{CR}$ & $\begin{array}{l}\mathrm{BEP} \times 2 \rightarrow \text { ICE } \\
\times 2 \text { and } \\
\text { high-dose } \\
\text { chemotherapy }\end{array}$ & 111 \\
\hline 10 & Non-Dysg & $\begin{array}{l}\text { II } \\
\text { AFP- } \\
\text { betaHCG }\end{array}$ & No & $\begin{array}{l}S \rightarrow B E P \times 2 \\
\rightarrow S\end{array}$ & 5 & $\begin{array}{l}\text { Growing } \\
\text { teratoma }\end{array}$ & $\begin{array}{l}\text { Abdominal } \\
\text { masses } \\
\text { peritoneal } \\
\text { diffusion and } \\
\text { hepatic } \\
\text { nodules }\end{array}$ & $\mathrm{CR}$ & S & 82 \\
\hline 11 & $\mathrm{IT}+\mathrm{AFP}$ & $\begin{array}{l}\text { III } \\
\text { AFP (1,438 } \\
\text { ng/ml) }\end{array}$ & Yes & $\mathrm{S} \rightarrow \mathrm{BEP} \times 4$ & 47 & $\begin{array}{l}\text { Mature } \\
\text { teratoma }\end{array}$ & Pelvic masses & $\mathrm{CR}$ & $S$ & 65 \\
\hline 15 & $\mathrm{IT}+\mathrm{AFP}$ & $\begin{array}{l}\text { IV AFP (1,440 } \\
\mathrm{ng} / \mathrm{ml})\end{array}$ & Yes & $\begin{array}{l}\mathrm{S} \rightarrow \mathrm{BEP} \times 2 \\
\rightarrow \mathrm{PD}\end{array}$ & 3 & Not done & $\begin{array}{l}\text { Peritoneal } \\
\text { diffusion }\end{array}$ & PD & $\begin{array}{l}\text { 2nd line } \mathrm{CT} \\
\rightarrow \mathrm{S} \\
\text { (teratoma)/34 } \\
\text { months } \\
\text { primitive neu- } \\
\text { roectodermal } \\
\text { tumor (pNET) }\end{array}$ & 34 (EX) \\
\hline
\end{tabular}

was 100\%, and 5-year EFS rates were $84.2 \%$ (95\% Cl: 73.4-96.6\%) for them all, $63.6 \%$ (95\% Cl: 40.7-99.5\%) for stage I, and $92.6 \%(95 \% \mathrm{Cl}$ : 83.2-100\%) for stages II-IV.

\section{1 | Overall results}

Thirty-nine of 49 (80\%) patients achieved CR after chemotherapy alone, and another 9 of 49 (total 98\%) after adding delayed surgery. Histology in the latter revealed fibronecrotic tissue in two (4\%), viable malignant cells in two (4\%), and teratoma in five (10\%). All but one of these patients was alive at the last follow-up (5-year OS 98.5\%, $95 \% \mathrm{Cl}$ : 95.6-100\%) and the 5-year EFS was 84.5\% (95\% Cl: 76.5-93.5\%) for all stages, 91.1\% (95\% Cl: 83.1-99.9\%) for stages II-IV, and 72.1\% (95\% Cl: 56.4-92.1\%) for stage I (Figs. 1 and 2). The 5-year EFS did not vary significantly with known prognostic factors ${ }^{11}$ : 5 -year EFS $85.8 \%$ (95\% $\mathrm{Cl}$ : 76.4-96.2\%) for patients $\geq 11$ years of age, $81.3 \%$ (95\% Cl: $66.3-$ 99.7\%) for those $<11$ years of age(log-rank test $P=0.564) ; 86.6 \%(95 \%$ Cl: 73.4-100\%) for Dysg, and 84.2\% (95\% Cl: 73.4-96.6\%) for NonDysg (log-rank test $P=0.614$ ). The median follow-up was 80 months.

\section{2 | Toxicity}

Chemotherapy was well tolerated and there were no toxic deaths, secondary leukemias, or cancers. One female had a severe skin 


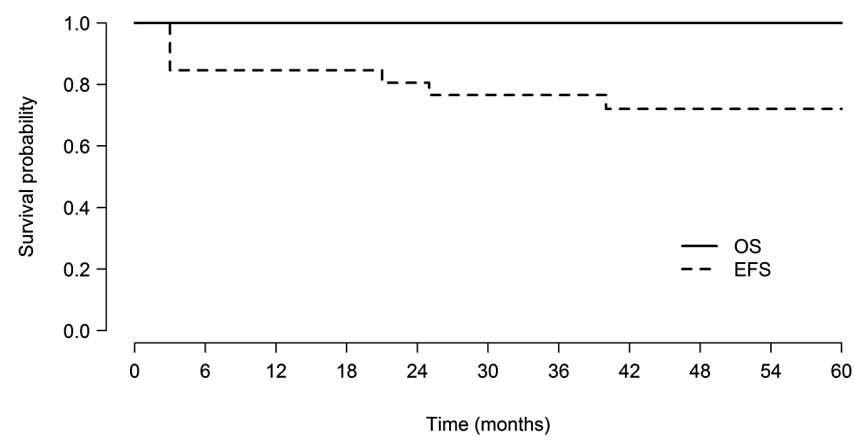

FIGURE 1 Event-free survival and overall survival-stage I

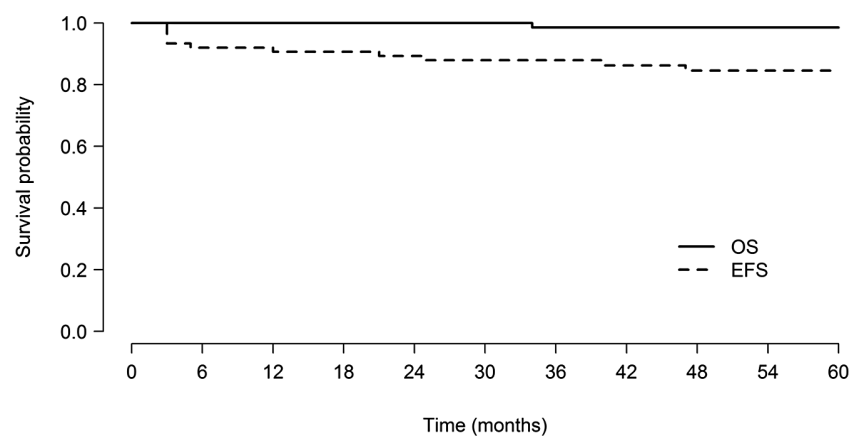

FIGURE 2 Event-free survival and overall survival-all stages

reaction after a second dose of bleomycin and the drug was subsequently omitted. Three patients had bilateral tumors and none underwent bilateral $\mathrm{OO}$ (one of them had iatrogenic amenorrhea). No lung or acoustic nerve impairments were identified after chemotherapy or during the follow-up. One pregnancy with offspring in good health has been reported.

\section{4 | DISCUSSION}

We describe the second Italian case series of MOGCT. Compared to the first, ${ }^{3}$ we found a higher number of cases because of the extended age of enrolment and greater awareness of some gynecologists, though pediatric cases are probably still underreported; a better survival (from a 33-month OS of $88.2 \%$ to a 5 -year OS of $98.5 \%$; and from 33-month EFS of $80.8 \%$ to a 5 -year EFS of $84.5 \%$ ), probably due to a more effective drug regimen; and a lower burden of treatment, since all NonDysg patients had previously received chemotherapy, and stage II Dysg patients had received radiotherapy.

This study confirms the excellent prognosis for Dysg patients, although our $P$-value was not significant when they were compared to Non-Dysg patients: none had distant metastases at diagnosis, and all stage II and III cases were cured without subsequent events. We recommend a strict follow-up with markers and ultrasound, reserving computed tomography and/or MRI for selected cases. Given the value of tumor markers for monitoring purpose, we prefer to use ultrasound to contain patients' radiological exposure during their follow-up. Even if Dysg patients lack informative AFP (often also betaHCG) levels, they should be followed up with ultrasound too, although Dysg relapses later and demands a prolonged follow-up. It has already been reported in adults that $>90 \%$ of relapses in Dysg patients occur within 3 years, and those in Non-Dysg patients appear within 2 years. ${ }^{12}$ This was true of our series too, and it is important to bear this in mind to ensure a proper follow-up (Table 3).

There is no consensus on the management of ovarian IT, and their inclusion in analyses on MOGCT is debated: approaches differ between adults and pediatric professionals, and even between pediatric series. ${ }^{13-16}$ We included IT with elevated AFP because central pathology review was not mandatory and there was a risk of missing some foci of YST within IT ${ }^{17}$ : in 2004, we chose to include IT with AFP level cutoff "high for age," which is why we had such a wide range. This is another controversial issue: some national pediatric groups (UK, COG) ${ }^{16-18}$ adopt an AFP cutoff for treating IT, while others do not. We acknowledge that having no cutoff can be misleading and an international agreement is needed.

The surveillance-alone strategy for Non-Dysg histotypes has recently been widely debated. Pediatric specialists and some European groups ${ }^{7,13,17,19-21}$ support this strategy in adults too. Pediatricians worry about the long-term treatment sequelae (neuro- and nephrotoxicity, lung fibrosis, hypertension, and etoposide-related secondary leukemia, ${ }^{22}$ ) and try to avoid chemotherapy. Cisplatin is measurable in the serum for years after exposure, and detectable in every bodily organ at autopsy. ${ }^{23,24}$ The cumulative prevalence of serious or lifethreatening chronic medical conditions by 45 years of age among pediatric cancer survivors is reportedly as high as $80 \%$, suggesting premature aging as a consequence of childhood cancer therapies. ${ }^{25}$ Some adult specialists are more cautious, especially for YST, and prescribe chemotherapy systematically because recurrences are rare, but potentially lethal. ${ }^{26,27}$ Another argument in favor of chemotherapy is concerned with the potential impact on fertility of further surgery for patients who relapse, ${ }^{26}$ and the need for more chemotherapy.

We realize that surveillance alone exposes some females to the risk of recurrence, but in our experience almost all of those who recur are rescued with standard-dose chemotherapy, with/without further surgery, with no impact on fertility. This seems a fair price to pay for the benefit to our patients spared any chemotherapy.

There is another point to consider in patients with residual/recurrent growing masses and a teratoma component in their original tumor: if their tumor markers remain normal, it is not a progression. The so-called chemotherapeutic retroconversion or growing teratoma ${ }^{28}$ is not so rare: Zagamé et al. reported an incidence of $12 \%$ in their pediatric and adult series, ${ }^{29}$ and it was $5 \%$ in our series. Growing teratoma should be managed with surgery, which is both diagnostic and the mainstay of therapy. Subsequent surgery may be needed to remove all localizations and late recurrences, ${ }^{28}$ so a prolonged follow-up is warranted. Awareness of growing teratoma is essential to avoid unnecessary chemotherapy. If surgery carries a significant risk, follow-up may be appropriate. Lesions can remain stable for years, but if they grow, a somatic malignant transformation should be ruled out. There is a risk of malignant transformation in every residual teratoma and debulking surgery is recommended, also for histological purposes, then the most appropriate treatment can be decided for the particular transformation underway. This applies to 
any residual disease after chemotherapy: the role of surgery is curative and diagnostic too, revealing different categories of residual disease (fibronecrotic tissue, teratoma, viable malignant cells).

Some issues are common to all histotypes. Whether surgical staging must be more extensive (as claimed by gynecological oncologists) or less so (as recommended by pediatric surgeons), ${ }^{4-8}$ remains unclear, and no randomized trials are available. ${ }^{19}$ The role of lymph node dissection is also debated ${ }^{5}$ : gynecological oncologists consider it fundamental (especially in Dysg) because dissemination is more often lymphatic than intraperitoneal. ${ }^{19}$ But without pathological tumor markers at diagnosis, ovarian masses may be indistinguishable from teratomas (for which lymphadenectomy is unnecessary). In our series, LNS was initially recommended, then omitted if the lymph nodes seemed normal. It is important to discuss these details to prompt pediatric surgeons to examine the nodes during surgery, perform PWC, and carefully assess the retroperitoneal lymph nodes on baseline computed tomography. Given the lack of conclusive scientific data on the most appropriate surgical staging, ${ }^{19}$ the patients' age and long life expectancy, and the high cure rates after relapses, as pediatric professionals we advise against excessively aggressive front-line surgery, and favor a minimal invasiveness. More extensive surgery should be reserved for relapsing patients, where necessary.

Noncompliance with surgical guidelines is a known issue for MOGCT and other neoplasms in pediatric and adult patients, 8,30-34 and was seen in our sample too. It is of special concern for patients with stage I. The multicenter Italian trial ${ }^{30}$ reported that stage IA Dysg (according to the FIGO classification) is incorrectly staged in $20 \%$ of adult cases, but about $15 \%$ of appropriately staged patients reportedly recur, ${ }^{35}$ so the benefit of accurate staging seems minimal. In the review by Palenzuela et al., ${ }^{31}$ none of the patients staged appropriately as IA and about $40 \%$ of those staged inappropriately recurred (though all relapsing patients could be cured). This was true of our series too. How to manage cases inappropriately classified as stage I is a controversial issue and many questions remain. There are too many options and no certainty concerning adjuvant chemotherapy (and its side effects) or surgical restaging; upstaging after appropriate surgery; the avoidance of any treatment until relapse (given the high cure rates afterwards), and the experience of recurrences irrespective of type of surgery performed; more intensive follow-ups for incorrectly staged cases. All the possible options have their pros and cons, and many issues need to be balanced and taken into account. Pediatric guidelines focus on minimal surgical invasiveness. Cases without PWC, proper surgical exploration, or tumor marker assays should reasonably be classified as stage II, and receive chemotherapy.

Our patients in stages II-IV were too few to identify any differences, but the proposed prognostic indicators ${ }^{11,36}$ suggest that females with stage IV MOGCT $>11$ years of age have a worse disease-free survival $(<70 \%)$. With only five metastatic cases, it is impossible to draw any conclusions, but the only patient with refractory malignant disease was in stage IV and $>11$ years of age.

The Children's Oncology Group ${ }^{7}$ had already compared the use of a compressed BEP regimen with standard BEP,26,37-39 and the Brazilian group omitted bleomycin in intermediate-risk patients. ${ }^{14}$ We delivered BEP in 4 days, with a single dose of bleomycin, and reduced the etoposide too. These dose reductions did not seem to influence survival, though randomized trials in adult male series showed worse results after reducing doses of bleomycin and etoposide ${ }^{40}$ and alternative combinations did not achieve better results in terms of survival or toxicity. ${ }^{23,39}$ Standard BEP remains the gold standard for adult GCT. ${ }^{38,39}$ Our BEP regimen was changed to minimize the risk of late sequelae and survival rates were excellent after low cumulative doses of etoposide and bleomycin. None of our patients have had secondary leukemia or severe late effects to date, though it is impossible to draw conclusions.

In conclusion, females with MOGCT generally have an excellent outcome, with a low burden of surgery and chemotherapy, and (hopefully) of late sequelae. Robust data and randomized trials are lacking, however, on surgical staging, surveillance for Non-Dysg with stage I, IT management, the "right" AFP cutoff, the type of BEP for young patients. As pediatric oncologists, we support the role of surveillance after minimal but accurate surgical staging, providing the case is handled by experts at specialized pediatric centers, as already reported by gynecological centers. ${ }^{31,41}$

\section{CONFLICT OF INTEREST}

The authors declare that there is no conflict of interest.

\section{REFERENCES}

1. Schenider DT, Terenziani M, Cecchetto G, Olson TA. Gonandal and extragonadal germ cell tumors, sex cord stromal and rare gonadal tumors. In: Schenider DT, Brecht IB, Olson TA, Ferrari A, eds. Rare Tumors in Children and Adolescents. Berlin: Springer-Verlag. 2012;327-402.

2. Olson TA, Murray MJ, Rodriguez-Galindo C, et al. Pediatric and adolescent extracranial germ cell tumors: the road to collaboration. J Clin Oncol. 2015;33:3018-3028.

3. Lo Curto M, Lumia F, Alaggio R, et al. Malignant germ cell tumors in childhood: results of the first Italian cooperative study "TCG91". Med Pediatr Oncol. 2003:41:417-425.

4. Rogers PC, Olson TA, Cullen JW, et al. Treatment of children and adolescents with stage II testicular cancer and stage I and II ovarian malignant germ cell tumors: a Pediatric Intergroup Study-Pediatric Oncology Group 9048 and Children's Cancer Group 8891. J Clin Oncol. 2004;22:3563-3569.

5. Billmire D, Vinocur C, Rescorla F, et al. Children's Oncology Group (COG). Outcome and staging evaluation in malignant germ cell tumors of the ovary in children and adolescents: an intergroup study. J Pediatr Surg. 2004;39:424-429.

6. Rescorla FJ. Pediatric germ cell tumors. Sem Pediatr Surg. 2012;21:5160.

7. Billmire DF, Cullen JW, Rescorla FJ, et al. Surveillance after initial surgery for pediatric and adolescent girls with stage I ovarian germ cell tumors: report from the Children's Oncology Group. J Clin Oncol. 2014;32:465-470.

8. Billmire DF, Rescorla FJ, Ross JH, et al. Impact of central surgical review in a study of malignant germ cell tumors. J Pediatr Surg. 2015:50:1502-1505.

9. Kaplan EL, Meier P. Non parametric estimation from incomplete observation. J Am Stat Assoc. 1958;457-481.

10. Schemper M, Smith TL. A note on quantifying follow-up studies of failure time. Control Clin Trials. 1996;17:343-346. 
11. Frazier AL, Hale JP, Rodriguez-Galindo C, et al. Revised risk classification for pediatric extracranial germ cell tumors based on 25 years of clinical trial data from the United Kingdom and United States. J Clin Oncol. 2015;33:195-201.

12. Kollmansberger C, Tansatad T, Bedard PL, et al. Pattern of relapse in patients with clinical stage I testicular cancer managed with active surveillance. J Clin Oncol. 2015;33:51-57.

13. Baranzelli M, Bouffet E, Quintana E, Portas M, Thyss A, Patte C. Non-seminomatous ovarian germ cell tumors in children. Eur J Cancer. 2000;36:376-383.

14. Lopes FS, Macedo CR, Aguiar Sdos S, et al. Lowered cisplatin doses and no bleomycin in the treatment of pediatric germ cell tumors: results of the GCT-99 protocol from the Brazilian Germ Cell Pediatric Oncology Cooperative Group. J Clin Oncol. 2016;34:603-610.

15. Mangili G, Sigismondi C, Lorusso D, et al. The role of staging and adjuvant chemotherapy in stage I malignant ovarian germ cell tumors (MOGCTs): the MITO-9 study. Ann Oncol. 2017;28:333-338.

16. Pashankar F, Hale JP, Dang $\mathrm{H}$, et al. Is adjuvant chemotherapy indicated in ovarian immature teratomas? A combined data analysis from the Malignant Germ Cell Tumor International Collaborative. Cancer. 2016;122:230-237.

17. Gobel U, Schneider DT, Calaminus G, Haas RJ, Schmidt P, Harms D. Germ-cell tumors in childhood and adolescence GPOH MAKEI and the MAHO study groups. Ann Oncol. 2000;11:263-271.

18. Murray MJ, Nicholson JC. $\alpha$-Fetoprotein. Arch Dis Educ Pract Ed. 2011;96:141-147.

19. Gershenson DM. Current advances in the management of malignant germ cell and sex cord-stromal tumors of the ovary. Gynecol Oncol. 2012;125:515-517.

20. Mann JR, Raafat F, Robinson K, et al. The United Kingdom Children's Cancer Study Group's second germ cell tumor study: carboplatin, etoposide, and bleomycin are effective treatment for children with malignant extracranial germ cell tumors, with acceptable toxicity. J Clin Oncol. 2000;18:3809-3818.

21. Patterson DM, Murugaesu N, Holden L, Seckl MJ, Rustin GJ. A review of the close surveillance policy for stage I female germ cell tumors of the ovary and other sites. Int J Gynecol Cancer. 2008;18: 43-50.

22. Travis LB, Fossa SD, Schonfeld SJ, et al. Second cancer among 40,576 testicular cancer patients: focus on long-term survivors. J Natl Cancer Inst. 2005;97:1354-1365.

23. Matei D, Brown J, Frazier L. Updates in the management of ovarian germ cell tumors. Am Soc Clin Oncol Educ Book. 2013.

24. Stoneham SJ, Hale JP, Rodriguez-Galindo C, et al. Adolescents and young adults with a "rare" cancer: getting past semantics to optimal care for patients with germ cell tumors. Oncologist. 2014;19:689-692.

25. Robison LL, Hudson MM. Survivors of childhood and adolescent cancer: life-long risks and responsibilities. Nat Rev. 2014;61-70.

26. Lhommé C, Leary A, Uzan C, Pautier P, Gouy S, Morice P. Adjuvant chemotherapy in stage I ovarian gem cell tumors: should indications and treatment modalities be different in young girls and adults? J Clin Oncol. 2014;32:2815-2816.

27. Mangili G, Sigismondi C, Lorusso D, Pignata S. Surveillance policy for stage IA malignant ovarian germ cell tumors in children and young adults. J Clin Oncol. 2014;32:2814-2815.
28. Amsalem H, Nadjari M, Prus D, Hiller N, Benshushan A. Growing teratoma syndrome vs chemotherapeutic retroconversion: case report and review of the literature. Gynecol Oncol. 2004;92:357360.

29. Zagamè L, Pautier $P$, Duvillard $P$, Castaigne D, Patte C, Lhommé C. Growing teratoma syndrome after ovarian germ cell tumors. Obstet Gynecol. 2006;108:509-514.

30. Mangili G, Sigismondi C, Lorusso D, et al. Is surgical restaging indicated in apparent stage IA pure ovarian dysgerminoma? The Mito group retrospective experience. Gynecol Oncol. 2011;121: 280-284.

31. Palenzuela G, Martin E, Meunier A, et al. Comprehensive staging allows for excellent outcome in patients with localized germ cell tumor of the ovary. Ann Surg. 2008;248:836-840.

32. Vicus D, Beiner ME, Klachook S, Le LW, Laframboise S, Mackay H. Pure dysgerminoma of the ovary 35 years on a single institutional experience. Gynecol Oncol. 2010;117:23-26.

33. Park JY, Kim DY, Suh DS, et al. Outcomes of pediatric and adolescent girls with malignant ovarian germ cell tumors. Gynecol Oncol. 2015;137:418-422.

34. Madenci AL, Levine BS, Laufer MR, et al. Poor adherence to staging guidelines for children with malignant ovarian tumors. J Pediatr Surg. 2016;51:1513-1517.

35. Gershenson DM, Wharton JT, Kline RC, Larson DM, Kavanagh JJ, Rutledge FN. Chemotherapeutic complete remission in patients with metastatic ovarian dysgerminoma. Potential for cure and preservation of reproductive capacity. Cancer. 1986;58:2594-2599.

36. Meisel, JL, Woo KM, Sudarsan N, et al. Development of a risk stratification system to guide treatment for female germ cell tumors. Gynecol Oncol. 2015;138:566-572

37. Pectasides D, Pectasides E, Kassanos D. Germ cell tumors of the ovary. Cancer Treat Rev. 2008;34:427-441.

38. Parkinson Ca, Hatcher HM, Earl HM, Ajithkumar TV. Multidisciplinary management of malignant ovarian germ cell tumors. Gynecol Oncol. 2011;121:625-636.

39. Hanna NH, Einhorn LH. Testicular cancer-discoveries and updates. $\mathrm{N}$ Engl J Med. 2014;371:2005-2016.

40. Grimison PS, Stockler MR, Thomson DB, et al. Comparison of two standard chemotherapy regimens for good-prognosis germ cell tumors: updated analysis of a randomized trial. J Natl Cancer Inst. 2010;102: 1253-1262

41. Solheim O, Kaern J, Tropé CG, et al. Malignant ovarian germ cell tumors: presentation, survival and second cancer in a population based Norvegian cohort (1953-2009). Gynecol Oncol. 2013;131: 330-335.

How to cite this article: Terenziani M, Bisogno G, Boldrini $\mathrm{R}$, et al. Malignant ovarian germ cell tumors in pediatric patients: the AIEOP (Associazione Italiana Ematologia Oncologia Pediatrica) study. Pediatr Blood Cancer. 2017;64:e26568. https://doi.org/10.1002/pbc.26568 